Thorax (1972), 27, 517.

\title{
Hydatid disease of the chest Report of 91 patients surgically treated
}

\author{
D. XANTHAKIS, M. EFTHIMIA DIS, G. PAPADAKIS, \\ N. PRIMIKIRIOS, G. CHASSAPAKIS,A. ROUSSAKI, \\ N. VERA NIS,A. AKRIVAKIS, and C. J.ALIGIZAKIS
}

The Thoracic Surgical Clinic, Sismanoglion Chest Hospital, Athens, Greece

\begin{abstract}
Ninety-one cases of hydatid disease of the chest are reported. Eighty-eight were involving the lung, two the chest wall, and one the mediastinum. All the patients were treated surgically. Conservative operations (simple removal of the parasite and closure of the remaining cavity) were performed in 78 patients, 37 unruptured and 41 ruptured cysts. Late postoperative complications occurred in eleven. In 10 patients, recurrent haemoptysis was the main symptom due to residual cavity in four, bronchiectatic changes in two, and unknown aetiology in four. In one patient, recurrence of multiple cysts occurred in the affected lobe. Radical operations were carried out in 10 patients, including segmental resection in four and lobectomy in six. Conservative operations were performed in all cases of unruptured cysts, with the exception of a giant cyst in which resection was the operation of choice. For ruptured cysts with mild infection conservative operation was also performed. Resection was necessary only in patients with ruptured cysts with suppuration, bronchiectatic changes, and giant cysts replacing a whole lobe. There was no mortality. We believe that conservative operation is the treatment of choice for hydatid disease of the lung. Indications for resection are very limited.
\end{abstract}

The problem of hydatid disease in Greece is still serious, particularly among the rural population.

During the last 10 years, 91 patients with hydatid chest disease were admitted to the Thoracic Surgical Clinic of Sismanoglion Chest Hospital. All the cases were surgically treated and the patients were followed up for from 2 to 10 years.

\section{MATERIAL}

The total number of patients admitted to our clinic between 1960 and 1970 was $91 ; 88$ cases involved the lung, one the mediastinum, and two the chest wall. In the 88 cases involving the lung, no liver hydatid disease was found, and similarly in the one located in the mediastinum no lung involvement was observed. The two cases involving the chest wall were recurrences following previous lung operations for hydatid disease. These recurrences occurred within one to three years. In the rural population 60 cases $(65.93 \%)$ were found whereas only $31(34.07 \%)$ were in urban districts. The distribution between the sexes is almost equal; 40 $(43.96 \%)$ were males and $51(56.04 \%)$ females. The peak incidence is found below the age of 40 (60 patients $-65.93 \%) ; 13$ patients were between 40 and 50 (14.29\%); 12 were between 50 and 60 (13.19\%); and only six were over the age of $60(6.59 \%)$.

1Reprint requests to C. J. A., 15 Kazneadon St., Athens
Of the 88 cases of lung cyst (Table I), 75 were single cysts and 13 were multiple. In the multiple cases, both lungs were frequently involved. The right lung was more frequently involved than the left, 56 and 32 cases respectively, and the lower lobes were more often involved than the upper. Thirty-six cysts were found in the right lower lobe and 19 in the left lower lobe. The right upper and middle lobes were involved in 20 cases and the left upper in 13 cases. Another characteristic finding was that large or giant cysts were often located in the upper lobes. Fifty-two cases were ruptured and 36 were unruptured (Table I). The size of the cyst did not play any significant role as far as rupture was concerned in our cases. On the contrary, rupture was more often found in the small than in the large cysts. Rupture into the bronchial tree was common (49 cases). Rupture into the pleura was found in three cases. In one of them it was iatrogenic due to aspiration of a giant cyst of the left lower lobe misdiagnosed as basal empyema.

Unruptured hydatid cysts were mostly discovered by chance radiography; 23 cases belong to this category (Table II). The main symptoms, when present, were cough, haemoptysis, and chest pain. Cough was the most frequent symptom in 
T A B L E I

LUNG DISTRIBUTION

\begin{tabular}{|c|c|c|c|c|c|c|c|}
\hline \multirow[b]{2}{*}{ Total } & \multirow[b]{2}{*}{ Single } & \multirow[b]{2}{*}{$\underset{\text { tiple }}{\text { Mul- }}$} & \multirow[b]{2}{*}{$\begin{array}{l}\text { Unrup- } \\
\text { tured }\end{array}$} & \multicolumn{2}{|c|}{ Ruptured } & \multirow{2}{*}{\multicolumn{2}{|c|}{$\begin{array}{l}\text { (R) Lung (L) Lung } \\
56 \\
(63.64 \%) \\
(36.36 \%)\end{array}$}} \\
\hline & & & & $\begin{array}{l}\text { Bron- } \\
\text { chial } \\
\text { Tree }\end{array}$ & Pleura & & \\
\hline 88 & 75 & 13 & 36 & 49 & 3 & $\begin{array}{l}\text { RUL } 10 \\
\text { ML } 10 \\
\text { RLL } 36\end{array}$ & $\begin{array}{l}\text { LUL } 13 \\
\text { LLL } 19\end{array}$ \\
\hline
\end{tabular}

T A B L E I I

SYMPTOMATOLOGY

\begin{tabular}{|c|c|c|c|c|}
\hline \multicolumn{3}{|c|}{ Predominant Symptoms } & $\begin{array}{l}\text { Unruptured } \\
\text { (Simple) Cysts }\end{array}$ & $\underset{\text { Cysts }}{\text { Ruptured }}$ \\
\hline $\begin{array}{l}\text { Asymptomatic } \ldots \\
\text { Cough .. } \\
\text { Haemoptysis } \\
\text { Pain } \\
\text { Coughing up of hyd } \\
\text { Dyspnoea } \\
\text { Spontaneous pneum } \\
\text { Allergic reaction } \\
\text { Purulent sputum } \\
\text { Clubbing of fingers }\end{array}$ & 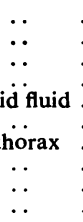 & $\begin{array}{l}\cdots \\
\cdots \\
\cdots \\
\cdots \\
\cdots \\
\cdots \\
\cdots\end{array}$ & $\begin{array}{r}23 \\
2 \\
2 \\
2 \\
6 \\
- \\
- \\
-\end{array}$ & $\begin{array}{r}\overline{37} \\
21 \\
27 \\
14 \\
12 \\
3 \\
2 \\
2 \\
2\end{array}$ \\
\hline
\end{tabular}

37 cases of ruptured cyst and in two cases of unruptured cyst. Haemoptysis was noticed in 23 cases, 21 ruptured cysts and two unruptured. Chest pain was found in 27 ruptured cases and in two unruptured. Coughing up of hydatid fluid was reported in 14 ruptured cases. Shortness of breath was noticed in 12 complicated ruptured cases and in six without complications. In the latter, the size of the cyst played a significant role in the appearance of dyspnoea and this was more often found in cases of giant cysts. Spontaneous pneumothorax as a first symptom was found in three cases. Allergic reaction was reported in two cases (one was a 5-year-old child) and severe anaphylactic reaction followed after coughing up clear hydatid fluid. Abundant purulent sputum was noticed in two cases and in these cases clubbing of the fingers was also noticed.

SPECIAL EXAMINATIONS AND TESTS (Table III) A Casoni intradermal test was carried out in 54 cases. We did not apply this test in cases where the radiological findings were typical. The test was positive in 51 and negative in three. The negative results were obtained in cases of unruptured cysts. An immediate reaction is not considered positive for hydatid disease; it may occur in certain skin diseases, allergic states, and some other helminthic infections. Of practical importance is the delayed reaction (first 24 hours) which occurs in $50 \%$ to $75 \%$ of patients. A complement fixation test was
T A B L E I I I

LABORATORY FINDINGS

\begin{tabular}{lll|ccc}
\hline & & Positive & Negative \\
\hline Intradermal test (Casoni) & &. & $\ldots$ & 51 & 3 \\
Complement fixation test (Weinberg) & $\ldots$ & 14 & 15 \\
Eosinophilia (more than $6 \%$ ) & $\ldots$ & $\ldots$ & 34 & \\
Pleural fluid (scolices) & $\ldots$ & $\ldots$ & $\ldots$ & 1 & \\
\hline
\end{tabular}

carried out in 29 patients. In 14 the test was positive and in 15 negative. Eosinophilia was present in 34 out of 91 cases. It has no direct diagnostic value but it may confirm the diagnosis when other common causes are excluded.

RADIOGRAPHIC FINDINGS (Table IV) A well-defined circular or oblong-shaped opacity within the lung is characteristic of the simple hydatid cyst. Thirtytwo out of 35 of our simple cases belong to this category. In three the outline of the shadow was blurred due to pericystic inflammatory reaction from an additional infection of surrounding lung parenchyma. Pneumopericyst or detachment sign was noticed in two cases. This picture is due to the presence of air between the adventitia and the endocyst. This partial separation of the endocyst from the adventitia gives a characteristic picture which is pathognomic and confirms, beyond question, the presence of echinococcus. If the cyst has ruptured into the bronchus and part of the fluid is evacuated, another unique radiographic finding may be obtained. This finding is of a cavity with a fluid level with the collapsed cyst floating in it (Camalote or waterlily sign). This sign was present in 20 ruptured cases. If suppuration occurs, then the picture is similar to that of a lung abscess and this was found in three cases. In two of them because of a valvular mechanism the adventitia was enormously distended, giving the picture of a giant cyst $ᄋ$ with fluid level. Sometimes, after rupture of a cyst into the bronchus, an inflammatory reaction

T A B L E I V RADIOGRAPHIC FINDINGS

\begin{tabular}{|c|c|c|}
\hline Radiographic Picture & Simple & Ruptured \\
\hline 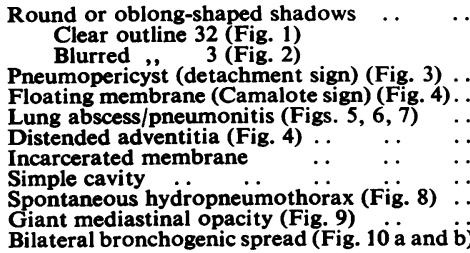 & $\begin{array}{l}1 \\
1 \\
1\end{array}$ & $\begin{array}{r}20 \\
1 \\
2 \\
23 \\
3 \\
3\end{array}$ \\
\hline
\end{tabular}




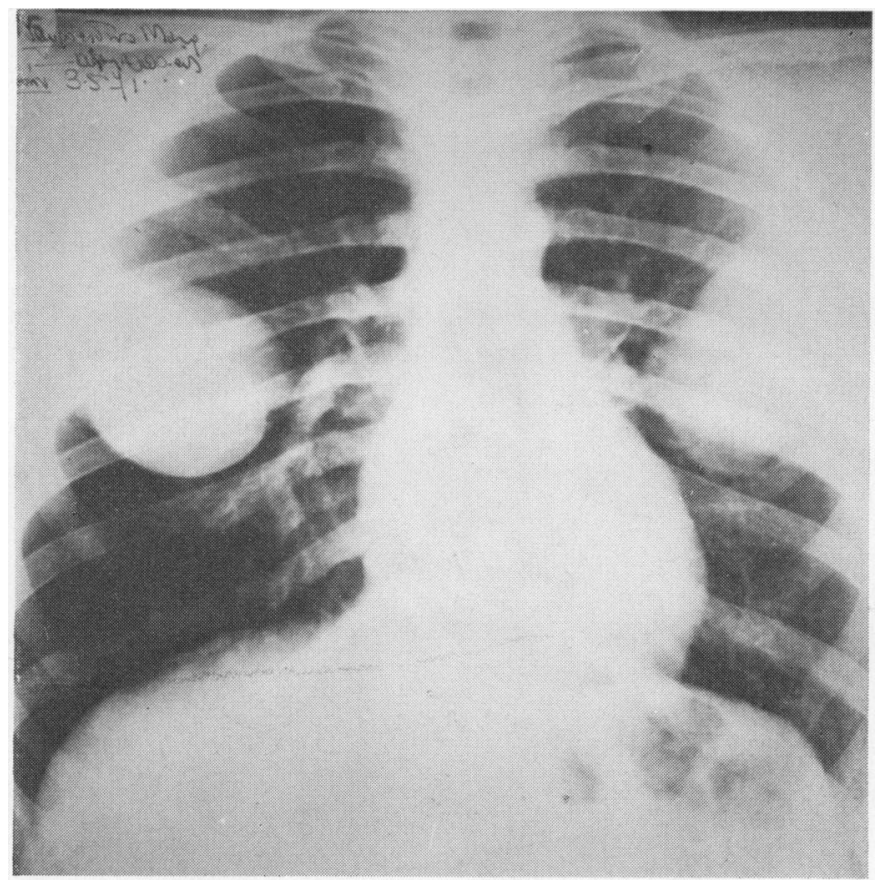

FIG. 1. Bilateral hydatid cysts. Simple removal in two stages.

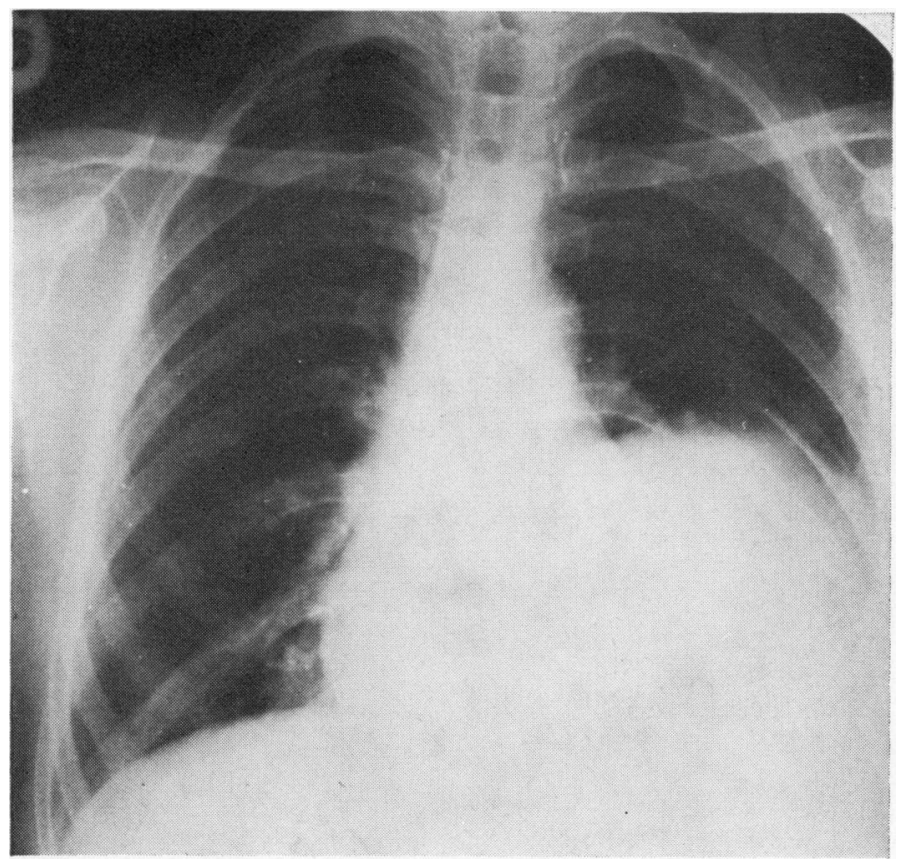

FIG. 2. Giant cyst left lower lobe. Blurred outline. Simple removal. 


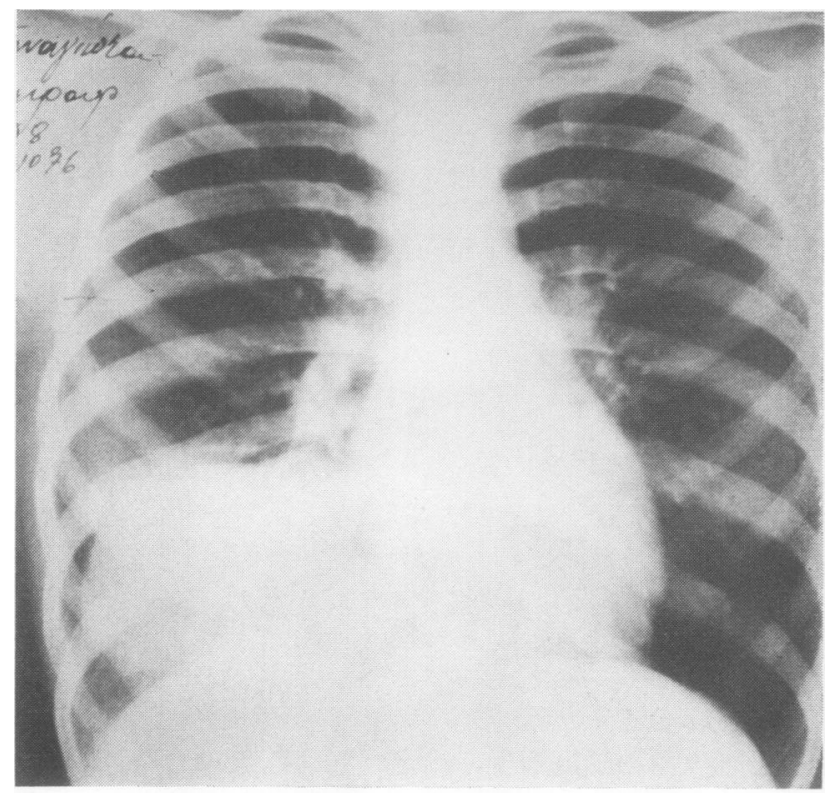

(a)

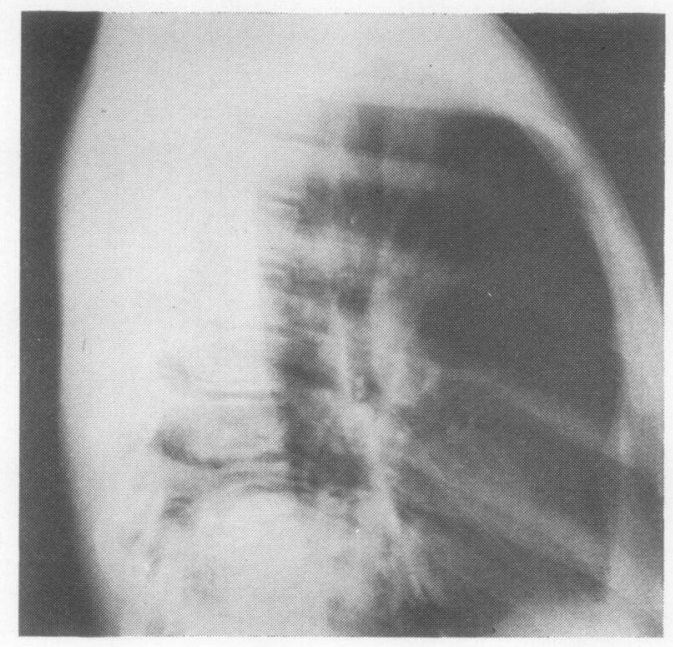

(b)

FIG. 3. Pneumopericyst (detachment sign). 


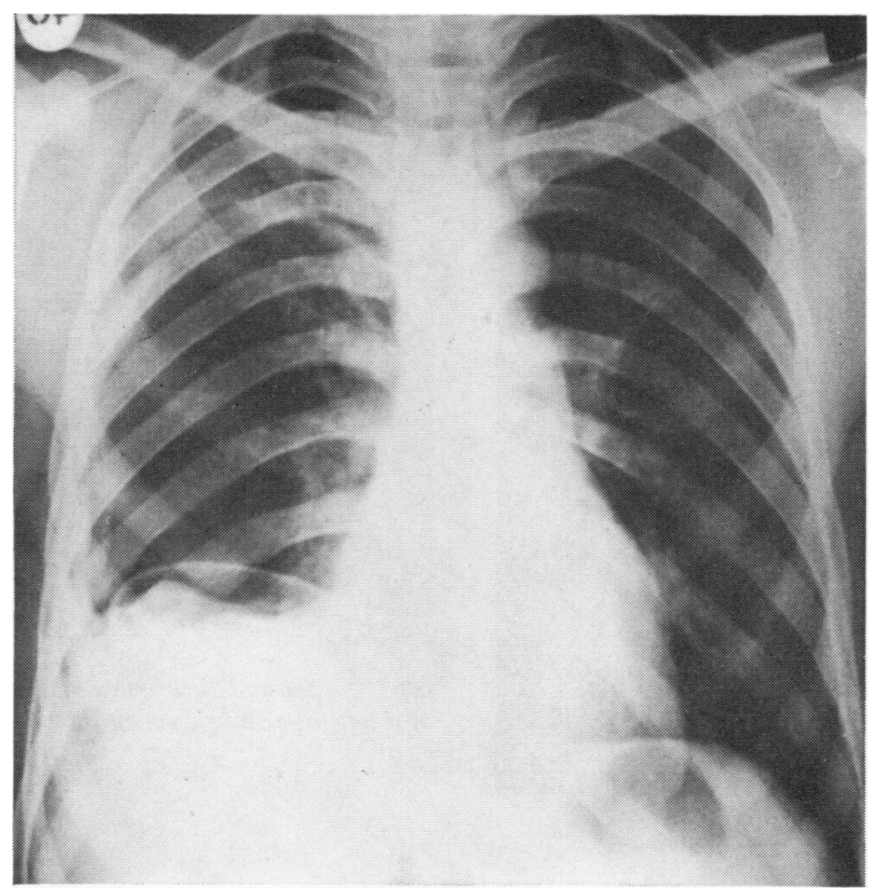

FIG. 4. Infected ruptured cyst of right lower lobe. Floating membrane and distended adventitia.

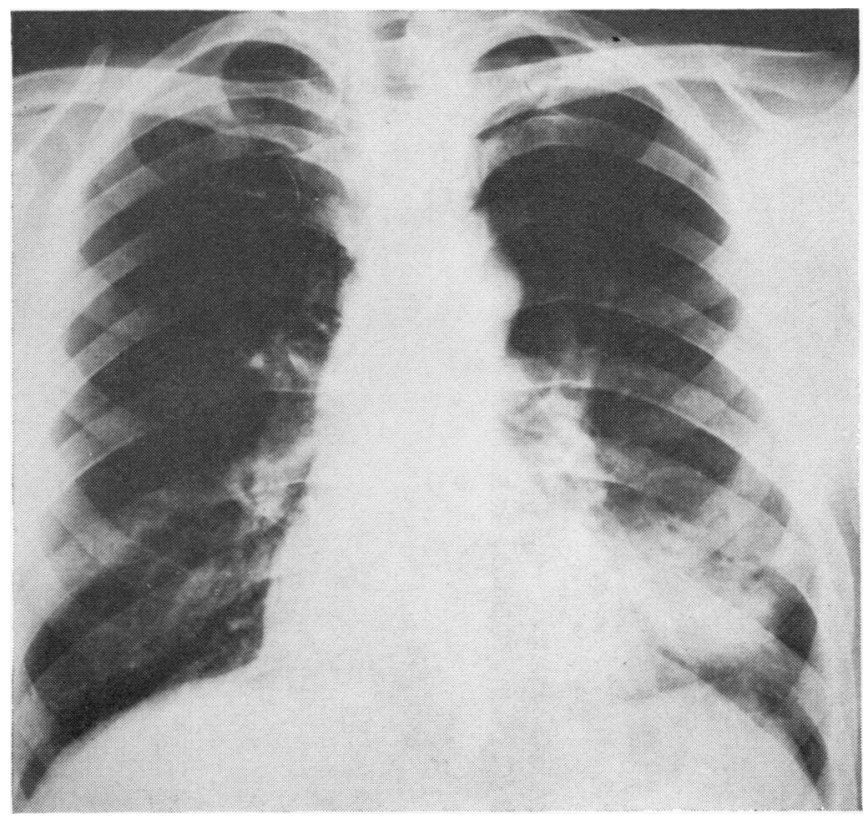

FIG. 5. Pneumonitis of the lingula. 
FIG. 6. Same case as in Fig. 5. Lateral view.

FIG. 8. Tension hydropneumothorax due to aspiration

of a left lower lobe cyst misdiagnosed as empyema.

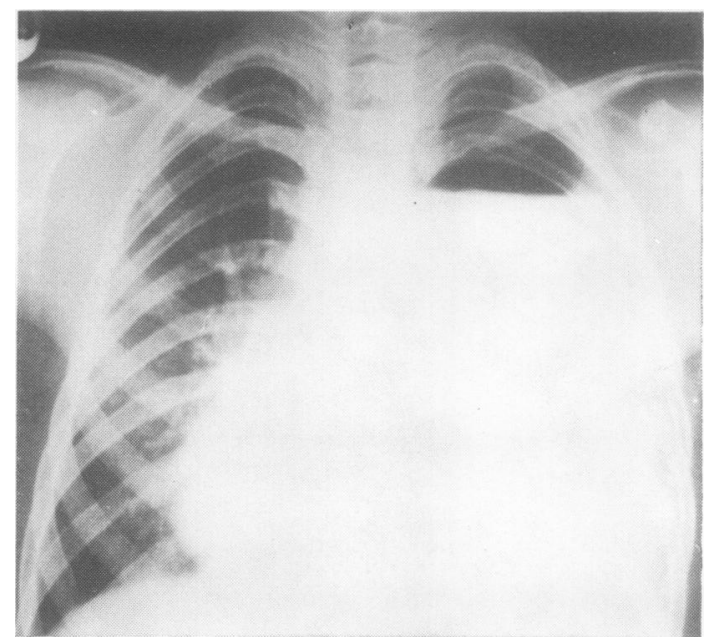

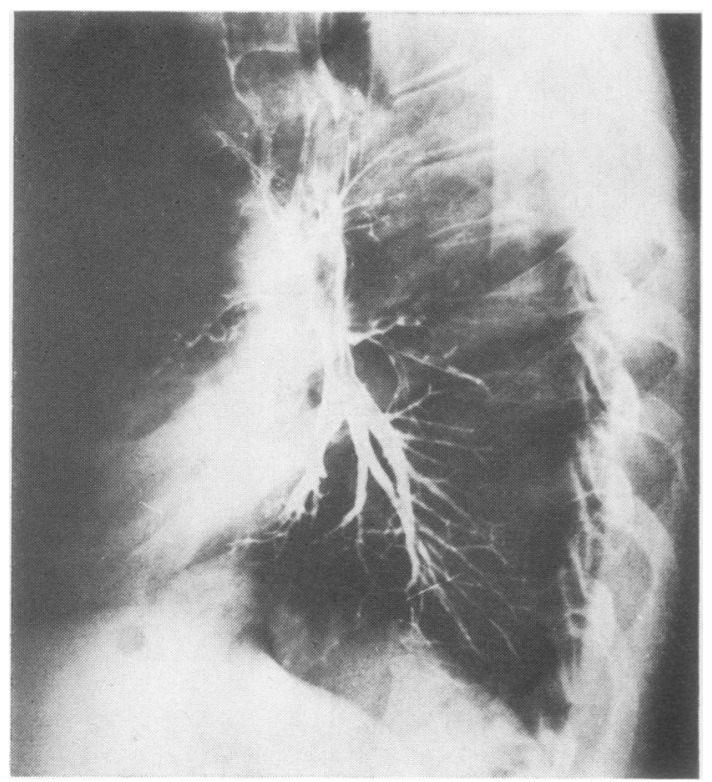

FIG. 7. Bronchogram shows obstruction of the lingula.

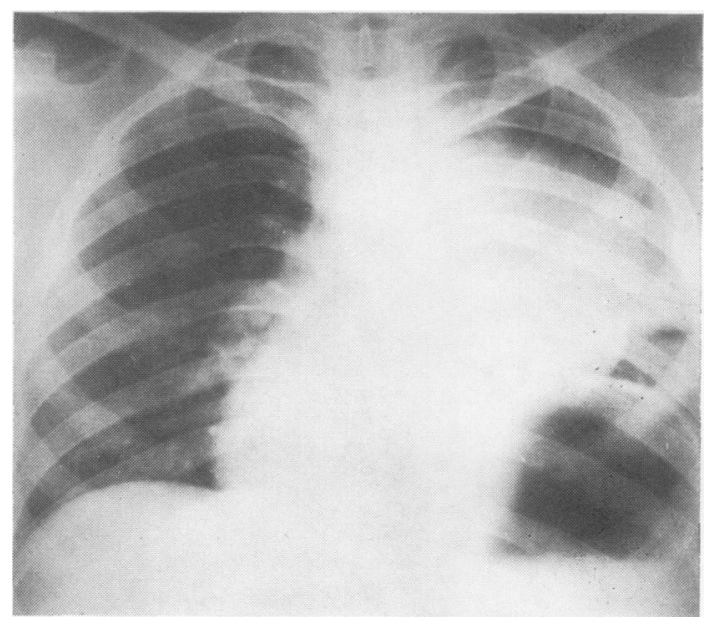

FIG. 9. Giant mediastinal cyst. Left phrenic paralysis. 

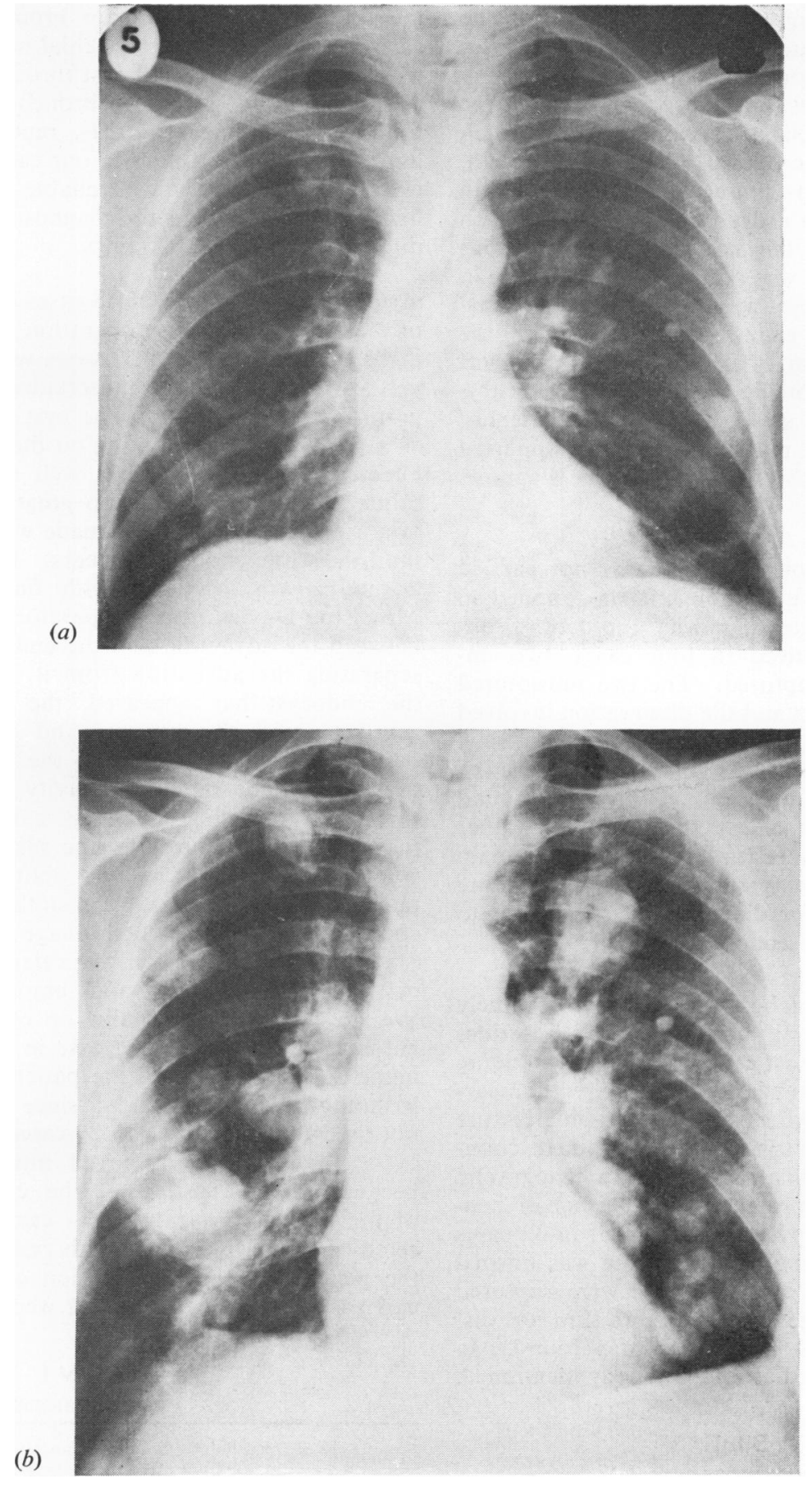

FIG. 10 (a). Ruptured cysts left lung. Small cyst right upper lobe. Simple removal. (b) Same patient two years later. Bronchogenic spread. 
may close the draining bronchus and imprison the membrane (incarcerated membrane). In these cases the definite regular outline is lost and there may be a blurred shadow that can easily be mistaken for a tuberculous focus or carcinoma (Ivanissevich sign). In 23 of our cases this picture was present. An empty cavity was noticed in three cases and during the operation a dry cavity was found with some remnants of the endocyst. Spontaneous hydropneumothorax was noticed in three cases. In one case where the cyst was located in the mediastinum there was a giant opacity located in the anterior mediastinum, with elevation of the left diaphragm due to phrenic nerve paralysis. In this case the picture was similar to that of a malignant neoplasm, and the phrenic paralysis supported this view. Only on thoracotomy was the diagnosis established.

BRONCHOGRAPHY Bronchography was not carried out as a routine investigation. It was applied in 17 cases, six unruptured and 11 ruptured. Bronchial block was noticed in four cases, two unruptured and two ruptured. The two unruptured cases were giant cysts and the observation involved the right upper and right lower lobes respectively. Bronchial displacement was found in five cases of unruptured cysts. Simple cavity filling was found in four cases and bronchiectatic changes in another four. All of them were ruptured cysts. The main indication for bronchography was a long-standing ruptured cyst, not for diagnostic purposes but to plan the extent of resection.

BRONCHOSCOPY Bronchoscopy was not routinely carried out. In small unruptured cysts it does not offer any diagnostic help. In long-standing ruptured cysts, particularly in those with incarcerated membrane where the radiographic picture is dubious and presents a diagnostic problem, bronchoscopy in combination with bronchography might exclude the presence of a bronchial neoplasm. Bronchoscopy was carried out in 39 cases (Table V). In 30, the bronchial tree was normal (25 were small size cysts and five were ruptured cysts). In nine large cysts, compression or displacement of the bronchial tree was found. In one involving the mediastinum, already mentioned,

T A B L E V

BRONCHOSCOPY

\begin{tabular}{llllr}
\multicolumn{4}{c}{ BRONCHOSCOPY } \\
\hline $\begin{array}{l}\text { Negative } \\
\text { Bronchial displacement }\end{array}$ & $\ldots$ & $\ldots$ & $\ldots$ & 30 \\
Bronchial compression & $\ldots$ & $\ldots$ & $\ldots$ & 5 \\
\hline
\end{tabular}

the rigidity of the left main bronchus was considered conclusive of a bronchial neoplasm. Protrusion of an unruptured cyst through a bronchial opening was not seen and bronchoscopic aspiration of membrane remnants, reported by some authors, was never found in our cases of ruptured cysts. This is the most reliable bronchoscopic finding in establishing the diagnosis in cases with dubious radiographic findings.

SURGICAL TREATMENT Of 88 cases of hydatid cyst of the lung, conservative operation was carried out in 78 cases (Table VI); 37 cysts were unruptured and 41 ruptured. The conservative operation is performed in this way. The cyst is usually seen as a grey-white soft swelling on the surface of the affected lobe. The lobe is well sealed off with saline swabs. If there is no great tension in the cyst a cross-like incision is made with a fine knife until the white endocyst appears. The flaps of the adventitia are lifted up with fine forceps. A Morriston-Davies rib rasparatory is inserted between the adventitia and the endocyst, carefully separating the adventitia from it. When most of the endocyst has appeared, the anaesthetist is asked to raise the pressure and delivery of the cyst occurs. The flaps of the adventitia are excised. In the remaining cavity usually two to three tiny bronchial openings can be seen and these are stitched up with fine silk in a figure of eight suture. The cavity is obliterated through purse string sutures starting from the bottom. The chest is closed with two drainage tubes.

If there is great tension we prefer to aspirate the cyst, evacuate the fluid, and remove the parasite. We do not inject formalin or other substances before aspiration. In one case in which $1 \%$ formalin solution was used the patient developed an irritating tracheobronchitis; since then we have not used this injection. In 29 cases of unruptured cysts, the cyst was removed intact but in six, because of the tension of the cyst, evacuation of the fluid by aspiration was carried out before removal. In two patients with cysts ruptured into the pleural cavity, decortication of the lung was carried out. Both these cases were long-standing

T A B L E V I

OPERATIVE METHODS

\begin{tabular}{|c|c|c|c|}
\hline Type of Operation & & Unruptured & Ruptured \\
\hline $\begin{array}{l}\text { Conservative operation } \\
\text { Radical operation: } \\
\text { Segmental resection } \\
\text { Lobectomy } \\
\text { Pneumonectomy ... }\end{array}$ & $\begin{array}{l}\cdots \\
\cdots \\
\cdots\end{array}$ & $\begin{array}{r}37 \\
1 \\
1 \\
\end{array}$ & $\begin{array}{r}41 \\
3 \\
5 \\
-\end{array}$ \\
\hline
\end{tabular}


ruptures into the pleural cavity. Each of the 41 ruptured cysts was infected and, after aspiration of the fluid and instillation of antibiotics, the bronchial openings were closed and the cavity was obliterated in the usual way. Excision of the whole adventitia was never carried out in either the ruptured or unruptured cysts. In none of our cases was haemorrhage encountered during removal of the parasite or obliteration of the cavity.

Resection of lung tissue was carried out in 10 cases (two unruptured and eight ruptured). Both the unruptured cysts were of a giant size (one was in a child) located in the right upper lobe and, after removal of the cyst, complete destruction of the lobe in one and of the posterior segment in the other was noticed. Right upper lobectomy and -segmental resection was performed. In another case resection of the anterior segment of the left upper lobe was necessary because of a tumourlike lesion found during operation. In the remaining cases resection was the operation of choice because of long-standing suppuration and bronchiectatic changes. Pneumonectomy was never necessary.

POSTOPERATIVE COMPLICATIONS Haemorrhage occurred in two cases (Table VII). The cysts were localized in the left upper and right lower lobes. Simple removal of the cysts was done and both patients started bleeding from the drainage tubes within the first or second postoperative day. Emergency thoracotomy was carried out. In one, a large haemothorax was present and, after evacuation of the clots, a small branch of an intercostal artery was found bleeding. In the other, intrapleural clots were removed and diffuse oozing was found. Both patients made an uneventful recovery. Suppuration of the closed cavity occurred in two cases; both were ruptured cysts with mild infection present at the time of the operation. High fever and purulent sputum were the main symptoms. The radiographic picture was consis-

\section{T A B LE VII}

POSTOPERATIVE COMPLICATIONS

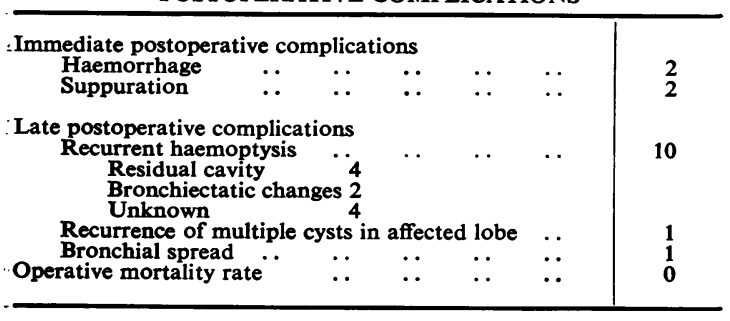

tent with lung abscess. With antibiotic treatment and postural drainage complete radiological clearance was achieved in 10 days. In late postoperative complications, haemoptysis occurred in 10 cases, between four and six months after operation. Complete investigation including bronchoscopy and bronchography was carried out. A residual cavity was found in four patients (Figs. 11 and 12) and bronchiectatic changes in two. In the remaining four, no abnormality was found and the cause of the haemoptysis was never established. No active measures were undertaken for small haemoptyses. Follow-up showed that the residual cavity present in four patients disappeared in three. In the remaining one, because of recurrence of the haemoptysis, the cavity was resected. In the two patients with bronchiectatic changes, the haemoptysis was not repeated and no further surgery was carried out.

Recurrence of multiple cysts in the same lobe was observed in one patient after conservative removal one year previously of a ruptured cyst of the left upper lobe. Numerous daughter cysts were found involving the whole lobe. A left upper lobectomy was carried out. Bronchial spread was noticed in only one case. The patient was operated on for multiple cysts of the left lung. Two years later the patient was readmitted with the clinical picture of respiratory failure.

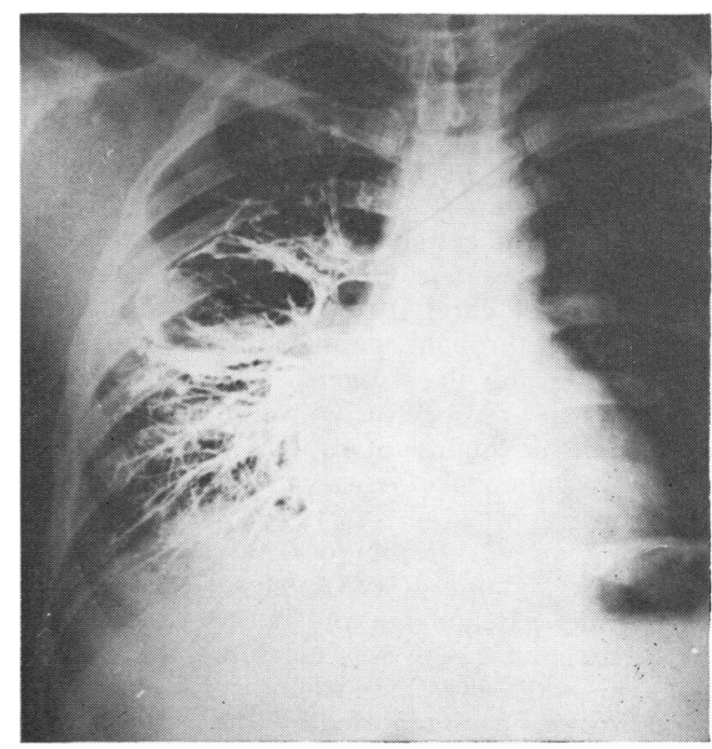

FIG. 11. Residual cavity right upper lobe after simple removal of hydatid cyst. 


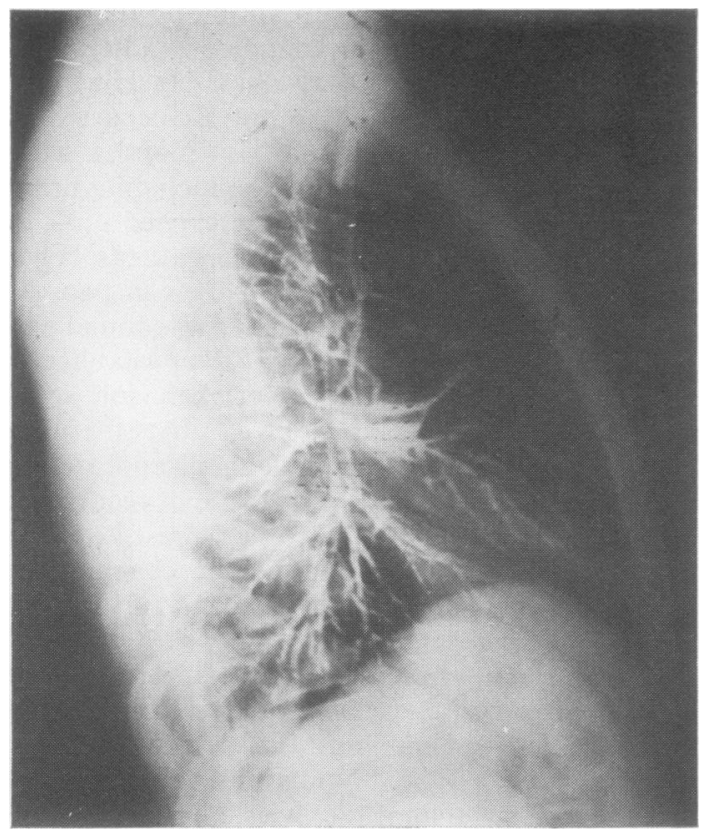

FIG. 12. Same patient as in Fig. 11. Lateral view.

Bronchogenic spread had occurred and the patient died. All these complications were observed after conservative operations.

In the resected cases no complication was noticed. The number of resected cases is too small to justify a conclusion about the superiority of one type of operation over another.

\section{DISCUSSION}

Surgery is the method of choice for treating hydatid disease of the lung, unless there is some contraindication to the operation. The present postoperative mortality rate is extremely low. Natural cure, it is true, may occur very occasionally through spontaneous evacuation of the parasite, but the dangers of bronchial spread are too great to justify such a waiting policy. There is also the possibility of rupture into the pleural cavity or pulmonary veins which compels immediate operation.

Several surgical techniques have been applied in the past. Thomas (1884) first suggested incision of the lung parenchyma and removal of the cyst. The remaining cavity was marsupialized into the thoracic wall and the wound was left open. Modifications were reported by Lindemann (1914), Dew (1928), Toole (1930), Makkas (1930), Makkas and Kourias (1931), Carayannopoulos (1934), Geroulanos (1935), and Kokkalis (1935).
A follow-up of the cases treated by these methods showed that in a considerable number of cases bronchocutaneous fistulae remained, spread of the disease occurred, and bronchiectatic changes leading to severe haemoptysis were noted.

New methods of treating hydatid lung disease were reported in 1947. These new methods can be divided into two groups:

(a) conservative, in which after a standard thoracotomy the parasite is removed, the bronchial openings are closed, and the cavity is obliterated (Barrett, 1947; Ugon, 1947; Allende and Langer, 1947; and

(b) radical, in which resection of involved lung parenchyma is carried out (Vaccarezza and Tricerri, 1951; Brea and Santas, 1951).

Susman (1953) stressed the following points in surgical treatment: complete removal of the cyst, avoidance of soiling and infection, obliteration of the space occupied by the cyst, closure of bronchial fistulae, and the need to achieve prompt reexpansion of the lung.

The parasite may be removed in various ways. Barrett (1947) aspirated the cyst before removal, to avoid rupture of the cyst. Ugon (1947) removed the entire parasite without aspiration. Barrett and Thomas (1952) accepted Ugon's technique but Susman (1953) doubted whether the risk of sudden rupture is justified. It is difficult to reconcile these views. We believe that if there is no great tension in the cyst, removing the parasite intact is the method of choice. Fontana (1948, 1951) reported a radical technique in which he removed the cyst with the adventitia. This technique is applicable to both ruptured and unruptured cysts. The disadvantage of this operation is haemorrhage during dissection of the pericyst from healthy lung parenchyma; also the remaining cavity cannot easily be obliterated.

Moreno (1953), because of difficulties in obliterating the cavity, recommended leaving the cavity open. Zafirakopoulos (1962), in a study of 32 surgically treated cases, underlined the advantages and dangers of the Fontana operation. The main indications, according to him, are in unruptured cysts with a small extension inside the lung parenchyma and in large cysts with thick or calcified adventitia.

Resection of the involved lung parenchyma is the most radical operation. Secondary inflammatory changes, hydatid bronchiectasis, contamination during the operation, and late postoperative complications (residual cavity) can be avoided by this method. Similar views were expressed by Logan and Nicholson (1948), 
Monod (1950), Vaccarezza and Tricerri (1951), Barrett and Thomas (1952), Ugon (1952), d'Abreu (1953), and Carayannopoulos (1953).

Susman (1953) limits resection to complicated cases with gross sepsis, recurrent haemoptysis or bronchiectasis. In simple cysts, whatever the size, he never advises resection unless haemorrhage occurs during a conservative operation, or a giant cyst has replaced most of the lobe.

Kourias and Tobler (1957 a, b), Zafirakopoulos (1962), Alivizatos, Romanos, Avlamis, and Bonellos (1963), Crausaz (1967), and Katsaras (1969) are also conservative and they limit resection to giant cysts or to ruptured cysts with infection and irreversible changes. Crausaz (1967) stresses the need for preservation of as much lung tissue as possible while dealing with hydatid disease. If lobectomy is performed the chances of the patient surviving future lung disease or further operation are reduced. Hydatid disease may recur as the patient may return to the area where he first became infected. Zafirakopoulos (1969) reported the results of microscopic examinations of 305 operative specimens (resections and conservative operations); he found in $4 \%$ living elements of the parasite in the first stage of evolution, in the layers of the adventitia and the surrounding lung parenchyma. Although the percentage is small he suggests a reconsideration of the present concepts of conservative treatment for ruptured cysts. His view is based on the pathological findings. A follow-up of our cases and of other series shows that recurrence is minimal.

We believe that conservative operation is the treatment of choice for all simple, small or large cysts of the lung. For giant cysts a decision must be made at the time of operation. If, after removing the parasite, the compressed lung parenchyma can be re-expanded, there is frequently no indication for resection. Dealing with giant cysts in children, we are also conservative and perform resection only in selected cases. In multiple cysts involving both lungs, we first operate on the side with the large cyst, because of the dangers of early complications, and after three weeks we operate on the other side. Simultaneous bilateral thoracotomy is best avoided. Katsaras (1969) points out that recent rupture into the bronchial tree should be treated conservatively. The allergic reaction is sometimes serious, particularly in children. Postural drainage, proper antibiotic treatment, and close observation of the patient for the first 15 days is necessary. It is a mistake to operate early. We agree with this opinion because if recurrence occurs in the same or in the other lung it cannot be prevented by an urgent operation. For ruptured cysts with mild infection conservative operation is not contraindicated. Postoperative infection of the cavity will respond to antibiotic treatment. Two examples of this complication have already been reported in our cases and there has been a satisfactory outcome.

In ruptured cysts with frank infection behaving as lung abscess, postural drainage and correct antibiotic treatment is a necessary preliminary to major surgery. Resection is the operation of choice. Resection is also indicated in cases of multiple daughter cysts (Fig. 13) involving one lobe presenting as a recurrence after a previous conservative operation. In the rare calcified cyst or when a diagnostic problem exists, such as a ruptured cyst with incarcerated membrane, resection is the treatment of choice. It is difficult even during the operation to differentiate the tumour-like appearance and feel of the lesion in the lung from a carcinoma or tuberculous disease.

Cysts of the mediastinum and pericardium are treated by simple removal.

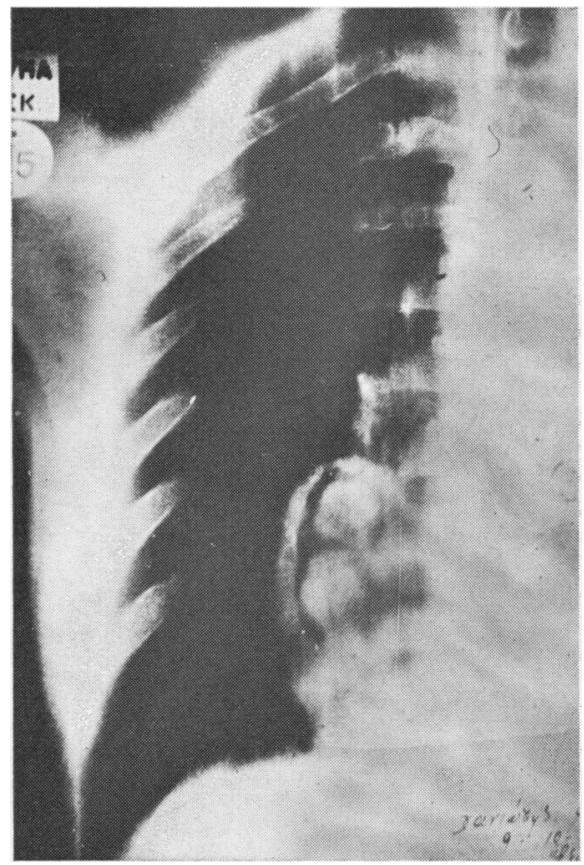

FIG. 13. Right lower lobe ruptured cyst with daughter cysts inside. 
A ruptured cyst into the pleural cavity requires emergency thoracotomy after the anaphylactic reaction is over. The objects of the operation are to remove the parasite (usually found floating in the pleural cavity), close the bronchial openings, obliterate the lung cavity, and re-expand the lung immediately. Even in neglected rupture with pyopneumothorax and daughter cysts in the parietal or visceral pleura, the same type of operation is indicated. The danger of recurrence is greater than in ruptured cysts into the bronchial tree; but this danger does not justify pleuropneumonectomy.

The problem of the residual cavity after spontaneous or operative removal of the parasite must also be considered. A waiting policy is indicated for at least six months. During this time the cavity may disappear. If, on the other hand, repeated haemoptysis or recurrent suppuration occurs, resection of the involved part of the lung is advisable.

\section{REFERENCES}

Alivizatos, C., Romanos, A., Avlamis, G., and Bonellos, C. (1963). Considerations chirurgicales sur le traitment de l' echinococcose pulmonaire. Rev. med. Moy. Or., 20, 244.

Allende, J. M., and Langer, L. (1947). Tratamiento de los quístes hidatídicos de pulmón. Bol. Acad. argent. cirug., 31, 536.

Barrett, N. R. (1947). The treatment of pulmonary hydatid disease. Thorax, 2, 21.

- and Thomas, D. (1952). Pulmonary hydatid disease. Brit. J. Surg., 40, 222.

Brea, M. M. J., and Santas, A. A. (1951). Resultados del tratamiento del quiste hidatidico del pulmon con especial referencia a los resecciones. Dia Medico (B. Aires), p. 632.

Carayannopoulos, G. (1934). Contribution to the diagnosis and treatment of hydatid cysts of the lung. Ann. Surg., 100, 125.

- (1953). Reported by Romanos, A. (1953). New aspects in the surgical treatment of hydatid disease of the lung. M.D. thesis, Athens.

Crausaz, P. H. (1967). Surgical treatment of the hydatid cyst of the lung and hydatid disease of the liver with intrathoracic evolution. J. thorac. cardiovasc. Surg., 53, 116.

d'Abreu, A. L. (1953). A Practice of Thoracic Surgery, 1st ed. Edward Arnold, London.

Dew, H. R. (1928). Hydatid Disease, its Pathology, Diagnosis and Treatment, p. 64. The Australian Medical Publishing Co. Ltd., Sydney.

Fontana, P. V. (1948). New operative method for hydatid cysts of the lung. Arch. Paed. Chirurg., 5, 37.
(1951). Traitement chirurgical du kyste hydatique de poumon. La méthode uruguayenne ou extirpation du périkyste. Arch. int. Hidatid., 12, 469.

Geroulanos, M. (1935). Report of a case of hydatid disease of the lung complicated with empyema. Bull. Greek Surg. Soc., 1, 57.

Ivanissevich, O., Pinero, T. A., Risolia, A. A., and Rivas, C. I. (1938). Secuelas cavitarias de los quistes hidatídicos del pulmón. Bol. y Trabajos Soc. Cirug. B. Aires, 22, 391.

Katsaras, E. (1969). Symposium in echinococciasis. Iatr. Athinai, 15, 523.

Kokkalis, P. (1935). Hydatid disease of the lung. Textbook of Surgery, Vol. A, p. 652.

Kourias, B., and Tobler, A. (1957a). Lés résultats à long terme des opérations pour échinococcose pulmonaire. A propos de 260 cas suivis. Mém. Acad. Chir., 83, 142.

- (1957b). L'avenir éloigné des opérés pour kyste hydatique du poumon. Arch. int. Hidatidose, 16, 323.

Lindemann - (1914). Reported by Zafirakopoulos, P. (1962). Indications on resections in the surgical treatment of hydatid disease of the lung. M.D. thesis, Athens.

Logan, A., and Nicholson, H. (1948). Hydatid disease of the lung. Thorax, 3, 1.

Makkas, M. (1930). Surgical treatment of hydatid disease of the lung. Bull. Greek Surg. Soc., p. 258.

— and Kourias, B. (1931). Über das weitere Schicksal der wegen Lungenechinokokkus operierten Kranken. Beitr. Klin. Chir., 153, 201.

Monod, R. (1950). Reported by Zafirakopoulos, P. (1962). Indications on resections in the surgical treatment of hydatid disease of the lung. M.D. thesis, Athens.

Moreno, I. G. (1953). A propos du traitement des kystes hydatiques du poumon. Mém. Acad. Chir., 79, 267.

Susman, M. P. (1953). Hydatid disease as it affects the thoracic surgeon. J. thorac. Surg., 26, 111.

Thomas (1884). Reported by Zafirakopoulos, P. (1962) Indications on resections in the surgical treatment of hydatid disease of the lung. M.D. thesis, Athens.

Toole, H. (1930). Echinococciasis in Greece. Greek Med., p. 449.

Tzamouranis, N. (1969). Symposium on echinococciasis. Iatr. Athinai, 15, 473.

Ugon, A. (1947). La lebectomia en el tratamiento de las secuelas del quiste hidatico de pulmon. Bol. Soc. Cirug. Urug., p. 465.

(1952). Tratamiento del quiste hidatico. Thorax Montevideo, May, p. 83.

Vaccarezza, O. A., and Tricerri, L. E. (1951). Resultados del tratamiento quirúrgico del quiste hidático de pulmón. A proposito de 41 casos tratados por resection de pulmón sin mortalidad. Pren. méd. argent., 38, 1079.

Zafirakopoulos, P. (1962). Indications of resections in the surgical treatment of hydatid disease of the lung. M.D. thesis, Athens.

(1969). Study of the indications of surgery in echinococciasis of the lung on the base of the pathology of the adventitia. Thesis for Lectureship, Medical School of Athens. 